\title{
Scoping Review: Pengaruh Mendengarkan Murottal Al-Quran terhadap Tingkat Stres Orang Dewasa
}

\author{
Edwina Sukmasari Yunus, ${ }^{1}$ Pandith A. Arismunandar, ${ }^{2}$ Dadang Rukanta ${ }^{3}$ \\ ${ }^{1}$ Medical Education Program, Faculty of Medicine, Bandung Islamic University \\ ${ }^{2}$ Departement of Public Health, Faculty of Medicine, Bandung Islamic University \\ ${ }^{3}$ Departement of Surgeons, Faculty of Medicine, Bandung Islamic University
}

\begin{abstract}
Abstrak
Murottal adalah pembacaan Al-Quran yang sesuai dengan tajwidnya ditambah dengan tartil (perlahan, tidak tergesa-gesa dengan mahraj yang jelas dan benar) dan dilagukan berdasar atas ilmu nagham. Sama halnya dengan terapi musik, banyak penelitian sebelumnya yang membuktikan bahwa salah satu efek Murottal Al-Quran adalah dapat menurunkan tingkat stres. Tujuan penelitian ini adalah mengetahui pengaruh murottal Al-Quran terhadap tingkat stres orang dewasa. Penelitian ini dilakukan dengan menggunakan metode scoping review yang merupakan pencarian data melalui penelitian-penelitian sebelumnya dengan memfiltrasi penelitian-penelitian tersebut berdasar atas PICOS: Population, Intereention, Clontrol and Study. Pada penelitian ini, artikel-artikel yang direview berasal dari jurnal nasional dan internasional yang berkaitan dengan pengaruh murottal Al-Quran terhadap stres. Berasal dari negara Malaysia dengan jumlah total artikel sebanyak 3 dan menggunakan dua database: Google Scholar dan Pubmed. Hasil scoping review ini menunjukkan bahwa mendengarkan murottal Al-Quran dapat menurunkan tingkat stres yang ditandai dengan penurunan hormon stres dan peningkatan gelombang alfa otak. Dapat ditarik kesimpulan bahwa terdapat pengaruh murottal Al-Quran terhadap tingkat stres.
\end{abstract}

Kata kunci: Al-Quran, murottal, stres

\section{Scoping Review: the Effect of Listening to Murottal Al-Quran on the Stress Level of Adults}

\begin{abstract}
Murottal is the recitation of the Quran according to its tajwid coupled with tartil (slowly, not in a hurry with clear and correct mahraj) and is chanted based on the study of nagham. The same with music therapy, many previous studies have shown that one of the effects of Murottal Al-Quran is reducing stress levels. The purpose of this study was to determine the effect of the murottal Al-Quran on the stress level of adults. This research was conducted using scoping review method, which is the search for data through previous studies by filtering these studies based on PICOS: Population, Intervention, Control and Study. In this study, the articles reviewed was chosen from national and international journals related to the influence of Murottal Al-Quran on stress. These articles are from Malaysia with a total of 4 articles, using two databases: Google Scholar and Pubmed. The results of this scoping review shown that listening to murottal Al-Quran reduces stress level characterized by the decrease in stress hormone and the increase in brain alpha waves. Therefore, it can be that there is influence of murottal Al-Quran on stress.
\end{abstract}

Keyword: Al-Quran, murottal, stress

Received: 8 ...; Revised: ...; Accepted: ...; Published: ...

Koresponden: Edwina Sukmasari Yunus. Program Pendidikan Sarjana Kedokteran, Fakultas Kedokteran Universitas Islam Bandung, Jl. Tamansari no. 22 Kota Bandung, Indonesia. 


\section{Pendahuluan}

Penelitian mengenai stres dan kesadaran kesehatan mental menjadi suatu topik yang popular pada dekade ini. Menurut Mental Health Foundation, 74\% manusia merasa sangat stres sehingga mereka kewalahan atau tidak mampu mengatasinya. Sedangan menurut American Psychological Association, generasi milenial mengalami tingkat stres tertinggi dalam kisaran umur 18 - 33 tahun dengan prevalensi lebih tinggi pada wanita. Penyakit yang berhubungan dengan stres juga diperkirakan menjadi salah satu alasan meningkatnya cuti sakit jangka panjang selama dekade terakhir di banyak negara Eropa. Hal ini terjadi dikarnakan tuntutan faktor akademis dan pekerjaan yang lebih kompetitif. Terutama di era modernisasi ini.

Selain itu, semenjak 11 Maret 2020, pandemi Covid-19 mengakibatkan perubahan secara drastis terhadap masyarakat luas yang berefek juga terhadap kesehatan mental. Pandemi ini mengakibatkan beberapa faktor yang meningkatkan stres seperti terjadinya peningkatan jumlah pemutusan hubugan kerja, penurunan ekonomi negara, inflasi, penutupan area rekreasi dan keharusan untuk menjaga jarak dari orang-orang terdekat. ${ }^{1}$

Kejadian ini berkontribusi besar terhadap peningkatan prevalensi stres diseluruh penjuru dunia. Sehingga, terjadinya peningkatan dampak negatif dari stres yang bermunculan. Seperti penurunan produktivitas masyarakat, pikiran putus asa dan hilangnya motivasi. Peningkatan stres ini juga mengakibatkan terjadinya peningkatan penderita gangguan mental pada masa pandemic ini. ${ }^{2}$

Menurut jurnal BMJ, peningkatan morbiditas psikologis yg terjadi semenjak pandemi covid-19 terbukti dikalangan warga Inggris. ${ }^{3}$ we report the mental health sequelae of the COVID-19 pandemic in a UK cohort and examine modifiable and non-modifiable explanatory factors associated with mental health outcomes. We focus on the first wave of data collection, which examined short-term consequences for mental health, as reported during the first 4-6 weeks of social distancing measures being introduced. DESIGN: Cross-sectional online survey. SETTING: Community cohort study. PARTICIPANTS: $\mathrm{N}=3097$ adults aged $\geq 18$ years were recruited through a mainstream and social media campaign between 3 April 2020 and 30 April 2020. The cohort was predominantly female ( $n=2618$ Di Indonesia sendiri, terjadinya peningkatan stress pada masyarakat didukung oleh Data Riset dan Teknologi Covid-19 Indonesia dimana 55\% masyarakat Indonesia yg tersebar di 8 kepulauan Indonesia mengalami stres. ${ }^{1}$

Dalam segi biologis dan ilmu kedokteran, stres merupakan faktor fisik, psikologis, dan/atau faktor lainnya yang dapat mengakibatkan ketegangan fisik. Sedangkan dalam aspek psikologis, menurut American Psychiatric Association, stres digambarkan sebagai perasaan kewalahan, khawatir, kehancuran, tekanan, kelelahan, dan kelesuan. Stres ini terjadi saat seorang individu berada dalam situasi terpaksa untuk bertindak. Stres juga merupakan suatu keadaan dimana seorang individu tidak dapat menanggung ketegangan mental yang diterima. Dengan kata lain, stres merupakan sutau proses kompensasi terhadap situasi atau kondisi yang dianggap baru atau asing ataupun mengancam. ${ }^{4}$

Saat tubuh mengalami stres, sistem saraf tubuh akan merespon dengan mengeluarkan hormon stres seperti adrenalin dan kortisol. Hal ini mengakibatkan jantung akan berdetak lebih cepat, otot menegang, tekanan darah meningkat, nafas menjadi lebih cepat dan panca indra kita akan menjadi lebih tajam. Stres itu dibutuhkan dalam takaran tertentu agar seorang individu dapat bereaksi cepat terhadap ancaman dan untuk bertahan hidup. Namun, kondisi stres dalam jangka panjang atau melebihi kapasistas individu dapat merubah keseimbangan hemodinamis tubuh dan dapat mengakibatkan penyakit secara fisik.

Tanda dan gejala dari stres berlebih secara umumnya dapat dibagi menjadi gejala kognitif seperti penurunan memori, ketidakmampuan berkonsentrasi dan khawatir yang terus menerus. Selain itu, ada gejala emosional, seperti moody, gampang marah, merasa kesepian dan terisolasi. Terdapat juga gejala secara fisik seperti akit dan nyeri kepala, diare atau sembelit, mual, dan muntah. 5

Terakhir adalah gejala perilaku, seperti makan terlalu banyak atau terlalu sedikit, tidur terlalu banyak atau terlalu sedikit, menjauhi orang - orang sekitar dan menunda atau mengabaikan tanggung jawab. Stres dalam jangka Panjang juga dapat menyebabkan penyakit secara mental maupun fisik. Seperti gangguan mood, major depression, post traumatic disorder, penyakit jantung, hipertensi, gagal jantung dan lain - lain. ${ }^{6}$

Hal yang dapat mengakibatkan stres disebut stressor. Dimana stressor ini bias berasal dari internal maupun eksternal. Seperti tuntutan pekerjaan, masalah hubungan dengan orang lain dan semua situasi, tantangan, kesulitan, dan harapan yang dihadapi seorang individu. Terdapat bermacam - macam cara untuk meminimalisir stres. Seperti dengan melakukan meditasi, mendengarkan musik, melakukan ritual spiritual, berekreasi, dimana initinya adalah melakukan suatu hal yang dapat meningkatkan ketenangan mental dan menurunkan kadar hormon stres dalam tubuh. Manajemen stres juga dapat meningkatkan pengeluaran hormon kebahagiaan seperti serotonin, oxytocin, dan endofrin. Sehingga menyeimbangkan kembali keadaan hemostasis dalam tubuh.?

Dalam perspektif Islam, terdapat banyak bahasan mengenai ketenangan dan bagaimana cara mencapainya. Maka dari itu peneliti diseluruh dunia banyak melakukan penelitian dalam segi perspektif islam ataupun menggunakan metode kajian islam. Salah satunya adalah efek murottal Al - Quran terhadap penurunan stres dan penyakit mental yang diakibatkan oleh peningkatan stres. ${ }^{8}$

Murrotal Al-Quran merupakan rekaman suara atau lantunan ayat-ayat suci Al-quran yang dilagukan oleh pembacanya dan didengarkan oleh pendengarnya maupun pembacanya. Mendengarkan pembacaan Al-Quran dengan murrotal memiliki ke khasan tersendiri yaitu terbentuknya alunan ritme yang harmonis. Sehingga dapat juga diartikan seperti musik yang dapat berefek terhadap beberapa area di 
otak. ${ }^{9}$

Beberapa penelitian menunjukkan bahwa pembacaan murottal dengan tartil memiliki banyak manfaat. Contohnya adalah memberikan dan mingkatkan rasa rileks, menyebabkan otak memancarkan gelombang theta dan juga alpha sehingga menimbulkan rasa tenang dan dapat menyembuhkan anksietas. Mekanisme murrotal ini diawali dengan penerimaan oleh organ pendengaran yang kemudian ditransmisikan ke area wernik untuk ditafsirkan oleh otak kemudian ke bagian asosiasi prefrontal untuk permaknaan peristiwa. ${ }^{8}$

Disamping itu impulse ini juga akan dihantarkan ke amigdala otak dimana merupakan bagian dari system limbik yaitu pusat pengaturan emosi pada otak. Dimana impulse ini dapat memberikan kesan positif pada hipokampus dan amigdala sehingga menimbulkan ketenangan perasaan dan suasana hati yang rileks. Sehingga dapat disimpulkan bahwa hubungan mendengarkan ayat suci Al - Quran dengan ketenangan adalah terbentuknya keadaan relaksasi pada tubuh. ${ }^{8}$

Sama halnya dengan mendengarkan musik, membaca ayat suci Al - Quran juga dapat menurunkan hormon stres dan menstimulasi pelepasan hormon kebahagiaan seperti endorphin dan juga serotonin. ${ }^{10}$ Menurut penelitian yang dilakukan di University Malaysia Pahang dengan judul "Mental and Spiritual Relaxation by Recitation of The Holy Quran" terdapat perbedaan signifikan diantara kelompok yang diberikan intervensi untuk mendengarkan musik tradisional dengan kelompok yang membaca ayat suci $\mathrm{Al}-$ Quran. ${ }^{8}$

Penurunan tingkat kebosanan, kelelahan, depresi, stres dan perilaku agresif manusia lebih permanen pada kelompok yang membaca ayat suci $\mathrm{Al}$ - Quran dibandingkan dengan yang mendengarkan musik tradisional. ${ }^{8}$ Hubungan antara ayat $\mathrm{Al}-$ Quran dengan emosi manusia diperkuat lagi dengan adanya penurunan kadar hormon kortisol darah bahkan pada pasien dengan penurunan kesadaran. Hal ini didukung dengan penelitian sebelumnya mengenai efek dibacakannya ayat suci Al - Quran pada pasien dengan penurunan kesadaran. Dimana pada penelitian tersebut menggunakan skala nyeri yang menggunakan visual analogue scale, faces pain rating scale, comfort scale dan pengukuran kadar hormon kortisol darah. Sehingga dapat disimpulkan bahwa terdapatnya efek dari murrotal $\mathrm{Al}-$ Quran dengan tingkat stres. ${ }^{10}$

\section{Metode}

Jenis penelitian yang dipergunakan adalah literatur review atau kajian pustaka terstruktur dengan menggunakan metode Scoping review. Fokus penelitian ini adalah Pengaruh Mendengarkan Murottal Al Quran terhadap Penurunan Tingkat Stres Orang Dewasa. Sampel yang digunakan dalam penelitian ini berjumlah tiga artikel penelitian dari jurnal internasional yang berkaitan dengan judul penelitian yang sesuai dengan kriteria inklusi dan eklusi.

Pencarian data melalui sumber database, yaitu
PubMed dan Google Scholar yang sifatnya resmi dan disesuaikan dengan judul penelitian, abstrak dan kata kunci yang digunakan untuk mencari artikel sebagai berikut.

Table 1 Database : Keywords dan Query

\begin{tabular}{lll}
\hline Database : Keywords dan Query & \\
\hline PubMed & Keyword: & $\begin{array}{l}\text { "Stress, } \\
\text { Psychological"[Mesh] } \\
\text { and Quran" }\end{array}$ \\
\hline Google Scholar $\quad$ Keyword: & $\begin{array}{l}\text { "Psychological Stress" } \\
\text { and "Al-Quran" }\end{array}$ \\
\hline
\end{tabular}

Literatur yang diakses dalam proses penelitian ini diskrining berdasar atas kriteria berikut: artikel penelitian diterbitkan dalam rentang waktu 10 tahun (2010-2020); tipe artikel menggunakan Randomize Control Trial, dan Control Trial. Artikel menggunakan bahasa Inggris. Artikel yang didapat dari kriteria PICOS: Population (Populasi, pasien, atau problem) orang dewasa yang terdapat pada jurnal artikel, Intervention/Exposure mendengarkan murottal $\mathrm{Al}$ Quran, Comparation tidak mendengarkan $\mathrm{Al}$ Quran dan mendengarkan suara jenis lain, Outcome terdapat penurunan pada tingkat stress orang dewasa, Study (tipe penelitian) Randomize Control Trial dan Clinnical Trial. Penelitian kualitas atau kelayakan pada penelitian ini didasarkan pada kriteria inklusi dan eklusi penelitian. Semua data berupa artikel penelitian yang sesuai dengan kriteria kelayakan di-review dan dianalisis secara kualitatif. Hasil keseluruhan artikel yang memenuhi syarat untuk di-review sebanyak tiga artikel.

\section{Hasil}

Hasil data dari penelitian mengenai efek Murottal Al-Quran terhadap tingkat stres yang sesuai dengan kriteria yang telah ditentukan sebelumnya terdapat 4 artikel. Artikel-artikel tersebut diambil dari 2 database yang berbeda, yaitu Google Scholar dan Pubmed. Pada database Pubmed dengan kata kunci "Stress, Psychological"[Mesh] and quran terdapat 2 artikel. Sedangkan pada database Google Scholar dengan kata kunci: "Psychological Stress" and "Al-Quran" terdapat 147 artikel. Jumlah jurnal secara keseluruhan sebanyak 149 artikel.

Kemudian dilakukan skrining pada jurnal sesuai kriteria inklusi dan kriteri eksklusi. Jurnal yang sesuai dengan kriteria inklusi pada database Google Scholar sebanyak 20 artikel dan Pubmed sebanyak 2 artikel. Sedangkan jurnal yang termasuk ke dalam kriteria eksklusi sebanyak 6 artikel dengan duplikasi sebanyak 1 artikel.

Dilanjut dengan hasil uji kelayakan berdasarkan PICOS: Population (orang dewasa sehat), Intervention (pemberian Murottal Al-Quran), Control (kelompok yang tidak diberi intervensi Murottal Al-Quran atau yang diberikan intervensi lainnya), Outcome (terdapat pengaruh Murottal Al-Quran terhadap stres), dan Study (original research articles (Randomized Controlled Trial (RCT), clinical trial, dan kuasi eksperimental) menghasilkan 4 artikel yang dapa 
dilihat dari diagram prisma berikut.
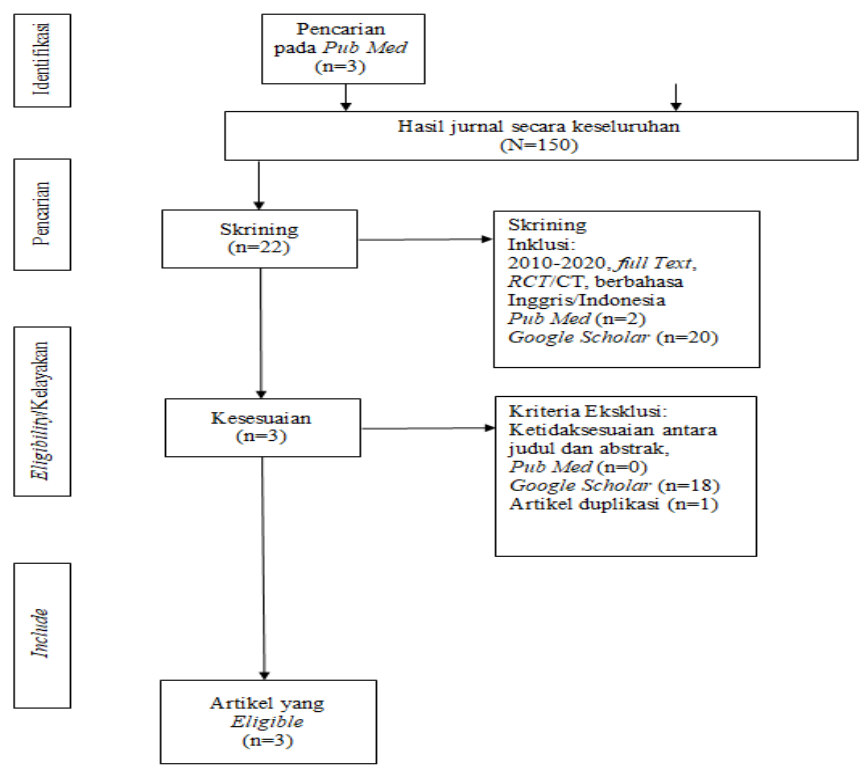

Tabel 4.1 Hasil Scoping Review Pengaruh Murottal Al-Quran terhadap Stres

\begin{tabular}{|c|c|c|c|c|c|}
\hline Judul/ Peneliti & Tujuan & Intervensi & $\begin{array}{c}\text { Metode } \\
\text { Pengukuran }\end{array}$ & Teknik Analisis & Hasil \\
\hline $\begin{array}{l}\text { Analyzing } \\
\text { Brainwaves } \\
\text { While Listening to } \\
\text { Quranic Recitation } \\
\text { Compared With } \\
\text { Listening to Music } \\
\text { Based on EEG } \\
\text { Signals } 2017 \\
\text { Malaysia }\end{array}$ & $\begin{array}{l}\text { Mengetahui } \\
\text { perbedaan respon } \\
\text { gelombang } \\
\text { otak antara } \\
\text { mendengarkan } \\
\text { Al-Quran dan } \\
\text { mendengarkan } \\
\text { Musik } \\
\text { Sampel 35 } \\
\text { mahasiswa }\end{array}$ & $\begin{array}{l}\text { Intenational } \\
\text { Affective Picture } \\
\text { System (IAPS) } \\
\text { beserta musik } \\
\text { (Mozart Music } \\
\text { K448, New age } \\
\text { and Jazz) dan } \\
\text { mendengarkan } \\
\text { Al-Quran } \\
\text { surat Yasin, } \\
\text { Al-Inshirah, Al- } \\
\text { Mu'awwidhatayn } \\
\text { dan Al-Ikhlas }\end{array}$ & $\begin{array}{l}\text { Gelombang } \\
\text { otak diukur, } \\
\text { dengan fokus } \\
\text { pada gelombang } \\
\text { Alfa dan Beta } \\
\text { untuk mengukur } \\
\text { ketenangan } \\
\text { subjek saat } \\
\text { mendengarkan } \\
\text { pembacaan } \\
\text { Alquran } \\
\text { dibandingkan } \\
\text { dengan musik } \\
\text { santai. }\end{array}$ & $\begin{array}{l}\text { Proses analisis } \\
\text { dimulai dengan } \\
\text { mengimpor } \\
\text { sinyal dari } \\
\text { 19-channel } \\
\text { EEG untuk } \\
\text { semua data, } \\
\text { termasuk data } \\
\text { emosi, Alquran, } \\
\text { musik, mata } \\
\text { tertutup dan } \\
\text { mata terbuka. } \\
\text { Kemudian, } \\
\text { pemotongan } \\
\text { pita frekuensi } \\
\text { untuk setiap } \\
\text { gelombang }\end{array}$ & $\begin{array}{l}\text { Hasil penelitian } \\
\text { menunjukkan } \\
\text { bahwa } \\
\text { magnitudo } \\
\text { alfa yang } \\
\text { lebih tinggi } \\
\text { dihasilkan } \\
\text { selama } \\
\text { mendengarkan } \\
\text { Al-Quran } \\
\text { dibandingkan } \\
\text { dengan } \\
\text { mendengarkan } \\
\text { musik. }\end{array}$ \\
\hline $\begin{array}{l}\text { EEG-Based } \\
\text { Emotion } \\
\text { Recognition } \\
\text { while Listening to } \\
\text { Quran Recitation } \\
\text { compared with } \\
\text { Relaxing Music } \\
\text { Using Valence- } \\
\text { Arousal Model } \\
2015 \\
\text { Malaysia }\end{array}$ & $\begin{array}{l}\text { Mempelajari emosi } \\
\text { manusia saat } \\
\text { mendengarkan } \\
\text { Al-Quran } \\
\text { dibandingkan } \\
\text { dengan mendengar } \\
\text { relaxing music } \\
13 \text { mahasiswa }\end{array}$ & $\begin{array}{l}\text { Stimulus emosi: } \\
\text { Kombinasi IAPS } \\
\text { (International } \\
\text { Affective Picture } \\
\text { System) dengan } \\
\text { lagu. Kemudian } \\
\text { mendengarkan } \\
\text { Murottal Al- } \\
\text { Quran Surat } \\
\text { Yasin dan Al- } \\
\text { Inshirah dilanjut } \\
\text { dengan relaxing } \\
\text { music }\end{array}$ & $\begin{array}{l}\text { klasifikasi emosi } \\
\text { mengikuti model } \\
\text { emosi Gairah- } \\
\text { Valensi dua } \\
\text { dimensi. Model } \\
\text { emosi untuk } \\
\text { mengenali empat } \\
\text { emosi dasar } \\
\text { Bahagia, Takut, } \\
\text { Sedih dan Tenang } \\
\text { dengan akurasi } \\
\text { rata-rata } 76.81 \%\end{array}$ & $\begin{array}{l}\text { Data emosi ketiga } \\
\text { belas subjek } \\
\text { diklasifikasikan } \\
\text { secara efisien } \\
\text { menggunakan MLP } \\
\text { dengan mean (M) } \\
\text { 76,81\% dan standar } \\
\text { deviasi (SD) 11,25 } \\
\text { persentase akurasi } \\
\text { tertinggi untuk } \\
\text { subjek } 3 \text { dengan } \\
\text { 90,9\% }\end{array}$ & $\begin{array}{l}\text { Secara umum } \\
\text { mendengarkan } \\
\text { Al-Quran dapat } \\
\text { mengubah } \\
\text { emosi manusia } \\
\text { dari negatif } \\
\text { menjadi positif } \\
\text { sama prinsipnya } \\
\text { dengan relaxing } \\
\text { music }\end{array}$ \\
\hline
\end{tabular}




Effect of Listening
to Sedative Music
and Quranic
Recitations on
Stress Level
Among IIUM
Undergraduate
Students
2018
Malaysia

untuk
mengevaluasi
efektivitas dua
intervensi berbasis
suara yaitu
mendengarkan
musik
penenang dan
mendengarkan
bacaan Al-Quran
terhadap tingkat
stres dengan
mengukur tingkat
stres sebelum
selama intervensi
dan sesudah.
77 mahasiswa

77 mahasiswa

\begin{tabular}{|c|c|}
\hline $\begin{array}{l}\text { Kelompok } \\
\text { pertama: } \\
\text { mendengarkan } \\
\text { musik penenang } \\
\text { (Beethoven: Piano } \\
\text { Sonata No. 14 in } \\
\text { C \# Minor, Op. } 27 \\
\text { No 2 Movement } \\
\text { No 1 (Moonlight } \\
\text { Sonata) yang } \\
\text { digabungkan dan } \\
\text { diulang sebanyak } \\
\text { tiga kali dengan } \\
\text { menggunakan } \\
\text { online audio } \\
\text { joiner berdurasi } \\
\text { 17 menit dan 59 } \\
\text { detik. } \\
\text { Kelompok kedua: } \\
\text { mendengarkan } \\
\text { Murottal Al- } \\
\text { Quran surah } \\
\text { Yasin durasi } \\
\text { 17menit 39 detik } \\
\text { Kelompok ketiga: } \\
\text { Duduk diam } \\
\text { dalam hening } \\
\text { selama 18menit }\end{array}$ & $\begin{array}{l}\text { Menggunakan } \\
\text { pre-test and post- } \\
\text { test questionnaire } \\
\text { :State-Trait } \\
\text { Anxiety Inventory } \\
\text { untuk mengukur } \\
\text { tingkat stress } \\
\text { peserta }\end{array}$ \\
\hline
\end{tabular}

$\begin{array}{ll}\begin{array}{l}\text { One way } \\ \text { repeated }\end{array} & \text { Hasilnya } \\ \text { measure of } & \text { menyoroti } \\ \text { ANOVA } & \text { bahwa } \\ \text { Two-way mixed } & \text { bacaan Al- } \\ \text { design analyses } & \text { Quran lebih } \\ \text { ofvariance } & \text { cenderung } \\ \text { model } & \text { mengurangi } \\ \text { Post-hoc } & \text { tingkat stres } \\ \text { pairwise } & \text { daripada } \\ \text { comparison } & \text { mendengarkan } \\ \text { untuk } & \text { musik penenang } \\ \text { menentukan } & \text { dan duduk } \\ \text { intervensi mana } & \text { diam. } \\ \text { yang paling } & \\ \text { signifikan } & \end{array}$
diam. signifikan

\section{Pembahasan}

Dari jurnal pertama dengan judul Analyzing Brainwaves While Listening To Quranic Recitation Compared With Listening To Music Based on EEG Signals didapatkan hasil analisis gelombang otak menunjukkan bahwa data Al-Quran menghasilkan magnitude alpha lebih tinggi daripada magnitudo beta, yang mencerminkan ketenangan dan relaksasi subjek saat mendengarkan murottal Al-Quran. Selain itu, data sampel yang mendengarkan musik rileksasi menghasilkan besaran gelombang beta dan alfa yang hampir sama tetapi tidak setinggi pembacaan Alquran. ${ }^{11}$ Gelombang Alfa memiliki frekuensi terletak antara 8-13 $\mathrm{Hz}$ dan berhubungan dengan kesadaran rileks. Selain itu, berperan juga dalam menyambungkan pikiran sadar dengan pikiran bawah sadar. Gelombang ini membantu kita untuk menjadi tenang dan menimbulkan perasaan relaksasi. Sedangkan gelombang beta $(14-26 \mathrm{~Hz})$ dikaitkan dengan pemikiran aktif dan fokus eksternal.

Gelombang ini aktif pada saat kondisi kita sedang sadar atau terjaga. Frekuensi ini terlihat pada saat kita menggunakan logical - analytical reasoning atau saat kita sedang melakukan atau mencoba untuk memecahkan suatu masalah. ${ }^{12}$ the research type of BCI was non-invasive, which capture the brain signals using electroencephalogram (EEG ${ }^{11}$ Kesimpulan dari artikel pertama mengindikasikan keadaan rileksasi lebih tinggi pada saat mendengarkan Al-Quran dibandingkan dengan keadaan sadar yang dibuktikan oleh hasil interpretasi gelombang otak alfa lebih tinggi dibandingkan gelombang otak beta. Mendengarkan musik rileksasi juga menimbulkan keadaan rileksasi yang dapat dilihat dari hasil gelombang otak alfa namun seimbang dengan keadaan sadar karena hasil dari magnitude gelombang alfa dan beta sama tinggi.
Dapat disimpulkan bahwa mendengarkan murottal AlQuran lebih meningkatkan keadaan rileksasi dengan hasil rata-rata gelombang otak alfa yang diproduksi lebih tinggi dibandingkan dengan hasil gelombang otak alfa yang dihasilkan setelah mendengarkan musik rileksasi. ${ }^{11}$

Artikel yang kedua dengan judul EEG-Based Emotion Recognition while Listening to Quran Recitation Compared with Relaxing Music Using Valence-Arousal Model menggunakan teknik analisis dan prosedur penelitian yang sama dengan artikel pertama. Dalam penelitian ini diselidiki efek mendengarkan pembacaan Al-Quran pada emosi manusia dengan sinyal yang diperoleh EEG. Selain itu, penelitian ini menambahkan prosedur yang beda dari penelitian pertama yaitu melakukan plotting klasifikasi emosi dasar Bahagia, Takut, Sedih dan Tenang. Dimana pengukuran dari klasifikasian emosi ini dilakukan sebelum dan sesudah mendengarkan murottal Al-Quran ataupun musk rileksasi. Bedanya dari hasil penelitian menunjukkan bahwa mendengarkan murottal Al-Quran dapat mengubah valensi dari emosi negatif menjadi emosi positif sama dengan musik rileksasi. Jadi untuk artikel ini tidak ada perbedaan hasil antara mendengarkan Al-Quran dan music rileksasi. ${ }^{13}$ Quran is Allah's words that are ultimately given to us human to benefit of. Although, Muslims are strongly believed that listening to Quran or reading it brings them to comfort, pleasure and confidence. Scientific evidence is still required to prove that scientifically. Human emotion can be recognized from voice, text, facial expression or body language. But those methods are susceptible to change and are not really accurate. Recently, electroencephalograms (EEG

Hasil dari artikel ketiga dengan judul Effect of Listening to Sedative Music and Quranic Recitations 
on Stress Level Among IIUM Undergraduate Students mendengarkan bacaan Al-Quran lebih cenderung mengurangi tingkat stres daripada mendengarkan musik penenang dan duduk diam. Beda dengan dua artikel sebelumnya dalam artikel ini ditambahkan sample kontrol dengan tidak mendengarkan apapun dan hanya duduk diam. Selain itu, didalam artikel ini tidak menggunakan interpretasi EEG melainkan menggunakan kuesioner Trait Anxiety Inventory (STAI). Kuesioner tersebut mengukur tingkat stres sebelum dan sesudah dilakukan intervensi. Limitasi dari artikel ini adalah variasi sample, waktu pengukuran dan rely on self report. Dimana variasi sampel terlalu sedikit dengan latar belakang sosioekonomi dan suku ras yang hampir semuanya sama. Selain itu waktu pengukuran juga hanya dalam satu hari dan hasil interpretasi hanya menggunakan kuesioner yang diisi oleh sample sendiri sehingga menunjukkan subjektivitas. ${ }^{14}$

\section{Simpulan}

Berdasarkan hasil review artikel menggunakan teknik scoping, mendengarkan Murottal Al-Quran mengakibatkan penurunan tingkat stres psikologis secara umum sehingga mendengarkan murottal AlQuran bisa dijadikan pilihan dalam terapi untuk mengatasi stres.

\section{Konflik Kepentingan}

Tim peneliti tidak memiliki konflik kepentingan.

\section{Ucapan Terima Kasih}

Dalam kesempatan ini kami mengucapkan terima kasih kepada Fakultas Kedokteran Universitas Islam Bandung, Dadang Rukanta, dan Pandith Arismunandar yang telah mendukung dan membantu dalam penulisan scoping review ini.

\section{Referensi}

1. Norfatin Nabila Raduian. Effect of Listening to Sedative Music and Quranic Recitations on Stress Level Among IIUM Undergraduate Students. Psych. 2018

2. Al-Galal SAY, Alshaikhli IFT, Rahman AWBA, Dzulkifli MA. EEG-based Emotion Recognition while Listening to Quran Recitation Compared with Relaxing Music Using Valence-Arousal Model. Int Conf Adv Comput Sci Appl Technol ACSAT. 2015

3. Irawan F. Penggunaan Ayat Al-Quran dalam Pengobatan Alternatif. Mekar KondangTangerang. 2017

4. Kemenkes. Direktorat Jenderal Pencegahan dan Pengendalian Penyakit Kementerian Kesehatan RI Tahun 2020. Germas. 2020

5. Jia R, Ayling K, Chalder T, Massey A, Broadbent E, Coupland C, et al. Mental health in the UK during the COVID-19 pandemic: cross-sectional analyses from a community cohort study. BMJ Open. 2020

6. Winurini S. Permasalahan Kesehatan Mental Akibat Pandemi COVID-19. Info Singk. 2020

7. Davies S. On Defining Music. Monist. 2012

8. Baldasaro MM. Pengaruh Murottal Al-Qur'an Terhadap Perubahan Tingkat Kecemasan Pasien Diabetes Mellitus Di Rsud Labuang Baji Makasar. Universitas Islam Negeri Alaudin Makassar. 2014

9. Fink G. Stress : The Health Epidemic of the 21st Century. Elsevier SciTech Connect. 2016

10. Wiegner L, Hange D, Björkelund C, Ahlborg G. Prevalence of perceived stress and associations to symptoms of exhaustion, depression and anxiety in a working age population seeking primary care. BMC Fam Pract. 2015

11. Haldorsen $\mathrm{H}$, Bak NH, Dissing A, Petersson B. Stress and symptoms of depression among medical students at the University of Copenhagen. Scand J Public Health. 2014

12. Marchand A, Haines VY, Harvey S, DextrasGauthier J, Durand P. Health and Stress Management and Mental-health Disability Claims. Stress Heal. 2016

13. Al-Galal SA, Fakhri Taha Alshaikhli I. Analyzing Brainwaves While Listening To Quranic Recitation Compared With Listening To Music Based on EEG Signals. Int J Perceptive Cogn Comput. 2017

14. Koudelková Z, Strmiska M. Introduction to the identification of brain waves based on their frequency. MATEC Web Conf. 2018

15. Kassymova G. Stress Management Techniques Recommended for Students. 2018

16. Yusoff MSB, Yee LY, Wei LH, Meng LH, Bin LX, Siong TC, et al. A study on stress, stressors and coping strategies among Malaysian medical students. Int J Students' Res. 2011

17. Triastuti NJ, Dewi IK. The relationship between listening to religious music and reading al-Qur'an to anxiety levels of medical students. Int $\mathrm{J}$ Res Med Sci. 2018

18. Yusoff MSB, Rahim AFA. The Medical Student Stressor Questionnaire ( MSSQ ) Manual An explanatory guide on stress and stressors in medical study to help you. 2014

19. Nayef EG, Wahab MNA. The Effect of Recitation Quran on the Human Emotions. Int J Acad Res Bus Soc Sci. 2018

20. Fazelniya Z, Najafi M, Moafi A, Talakoub S. The Impact of an Interactive Computer Game on the Quality of Life of Children Undergoing Chemotherapy. Iran J Nurs Midwifery Res. 2018

21. Shaltout M. The Holy Quran and Cosmology. International Commission on Scientific Signs. 2014

22. Sakamoto M, Ando H, Tsutou A. Comparing the effects of different individualized music interventions for elderly individuals with severe dementia. Int Psychogeriatrics. 2013

23. Hanafi M, Muhammad F, Wulandari D. The Effect of Quran Recitation to Pain and Comfort Feeling on Patients with Reduced Consciousness in UNS Hospital. KnE Life Sci. 2019

24. Yikealo D, Yemane B, Karvinen I. The Level of Academic and Environmental Stress among 
College Students: A Case in the College of Education. Open J Soc Sci. 2018

25. Shahsavarani AM, Azad E, Abadi M, Kalkhoran MH. Stress: Facts and Theories through Literature Review. Int J Med Rev. 2015

26. Allen AP, Kennedy PJ, Cryan JF, Dinan TG, Clarke G. Biological and psychological markers of stress in humans: Focus on the Trier Social Stress Test. Neurosci Biobehaviour. 2014

27. Ajorpaz NM, Services H. Effects of Recitation of Holy Quran on Anxiety of Women before Cesarean Section: A Randomize Clinical Trial. Qom Univ Med Sci J. 2010

28. Khan N, Ahmad NB, Beg AH, Fakheraldin MAI, Alla ANA, Nubli M. Mental and spiritual relaxation by recitation of the holy Quran. 2nd Int Conf Comput Res Dev ICCRD. 2010
29. Vaghefi M, Nasrabadi A, Hashemi Golpayegani S, Mohammadi M, Gharibzadeh S. Nonlinear analysis of electroencephalogram signals while listening to the holy Quran. J Med Signals Sens. 2019

30. Alzeeralhouseini AMR. Emotion Detection While Listening To Quran Revitation Using EEG and ECG by Amjad M.R Alzeeralhouseini. Computer Science Kulliyyah of Information and Communication Technol. 2016

31. Wardi R, Ifdil I. Stress Conditions of Students in Resolving Thesis. Guid J Ilmu Pendidikan, Psikologi, Bimbing dan Konseling. 2016

32. Rahim NA. Sound Therapy Using Quranic Verse in Increasing the Calmness and Reducing Stress on Final Year Students in Unimas. 2015 